Zvi Bekerman, Thomas Geisen (eds)

\section{International Handbook of Migration, Minorities and Education: Understanding Cultural and Social Differences in Processes of Learning}

New York: Springer, 2012, 753 str.

DOI: 10.11567/met.30.1.5

Zbornik International Handbook of Migration, Minorities and Education: Understanding Cultural and Social Differences in Processes of Learning jedan je od prvih usmjerenih na prikupljanje znanja i iskustava iz različitih društveno-političkih sredina, a cilj mu je, kako u uvodnom dijelu naglašavaju glavni urednici, rasvijetliti »moguće izazove koji proizlaze iz kulturnih diskursa o obrazovnim procesima manjinskih i migrantskih skupina« (str. 3). Urednici Zvi Bekerman, profesor antropologije obrazovanja na Hebrejskom sveučilištu u Jeruzalemu, i Thomas Geisen, viši predavač i istraživač na Fakultetu socijalnog rada Sveučilišta primijenjenih znanosti Sjeverozapadne Švicarske, nadaju se da će ovim zbornikom pridonijeti razvoju kritičke teorije obrazovanja razgraničene od metodološkog individualizma (ali moguće i u ovom području relevantnog i prisutnog metodološkog nacionalizma) u obrazovnim istraživanjima i praksi usmjerujući se izravno na kulturu i društvenost.

Podijeljen na šest osnovnih tematskih cjelina, zbornik okuplja radove pedesetak autora koji predstavljaju rezultate raznih studija i istraživanja utemeljenih na različitim teorijskim postavkama te provedenima u okvi- ru višestrukih metodoloških tradicija (kvalitativnih i kvantitativnih). Ti su radovi usmjereni na prikazivanje odnosa obrazovanja i obrazovne prakse etničkih manjina i migranata na više od dvadeset različitih lokacija diljem Europe, Amerike, Australije i Azije.

Prva cjelina Culture, Difference and Learning ujedno je i najveća te sadržava jedanaest poglavlja. Radovi se odnose poglavito na složene odnose kulture i obrazovanja. Primjerice analizira se uloga obrazovanja u migracijskim procesima, prikazuju se migracijske teorije u kontekstu razumijevanja kulturnih različitosti, ispituje se učinak koncepta etničnosti te mogućnosti »upravljanja « različitostima u okviru obrazovnih programa. Teorijski i empirijski radovi u ovoj cjelini usmjereni su na različite aspekte obrazovanja raznih aktera, odnosno ciljanih skupina - od djece iz migrantskih obitelji do odraslih migranata, fokusirajući se na obrazovne procese $u$ ranom djetinjstvu, mladosti i odrasloj dobi. Sva su poglavlja kritički usmjerena na »nepromišljeno prihvaćanje kulture kao dane ili fiksirane, uključujući i razna značenja pojma kulture i njezinih uloga « (str. 11), ali i na olakšavanje razumijevanja kompleksnog odnosa migracija, kulture, različitosti i obrazovanja.

Druga cjelina Education in Multilingual Societies sastoji se od osam poglavlja/radova čiji je fokus ponajprije na problemima s kojima se susreću pripadnici različitih manjina u pogledu identifikacije i jezika $u$ formalnom obrazovanju. U jednoj skupini radova ispituje se status materinskog jezika nacionalnih manjina i autohtonih etničkih skupina u Estoniji i Hrvat- 
skoj te na teritoriju Nanvut u Kanadi, u drugoj se približavaju iskustva migrantskih studenata u Irskoj i Kanadi, dok se u trećoj autori bave ulogom i stavovima roditelja pripadnika etničkih manjina u pregovaranju o položaju njihove djece $u$ obrazovnim sustavima Izraela i Kanade. Zajednička karakteristika ove skupine radova upravo je referenca na višejezično okruženje, odnosno iskustvo iz višejezičnog društva, u kojem ulogu u definiranju statusa manjinskog jezika u obrazovanju ima više aktera - od roditeljâ, učiteljâ i učenikâ do kreatorâ društvenih politika.

Za razliku od prve dvije cjeline, u kojima se raspravlja o više općenitim teorijskim pitanjima i problemima manjinskih jezika, treća cjelina Heterogeneity and Learning in Schools usmjerena je na formalne obrazovne sustave i obrazovne politike u Švicarskoj, Velikoj Britaniji, Njemačkoj, Kanadi, Švedskoj, SAD-u, Grčkoj, Portugalu, Argentini i Španjolskoj. Polazeći od različitih teorijski i metodološki utemeljenih premisa, autori raspravljaju o povezanosti etnifikacijskih procesa i obrazovanja nudeći polazišta za »razumijevanje transnacionalne povezanosti politika i ideologija te shvaćanje ograničenja nacionalnih kreiranja obrazovnih politika i praksi vidljivih u školskim sustavima" (str. 3), pri čemu imaju u vidu da su škole prostor u kojem se reproduciraju »vrlo specifične subjektivne predodžbe u specifično nacionalnom kontekstu « (str. 321). Irina Schmitt u uvodnome dijelu ističe da se radovi u ovoj cjelini odnose na probleme u konceptualizaciji obrazovanja u novim i starim imigracijskim društvima, povijesno utemeljenu, ali i dalje aktualnu »borbu oko predstavljanja etnicizirane i manjinski određene djece i mladih «(str. 321), reprodukciju nejednakosti i diskriminacije te, s druge strane, metodičke i didaktičke strategije odnošenja prema različitostima u razredu. Kako i glavni urednici ističu, glavni je doprinos ovih radova u tome što upozoravaju na veliku potrebu za novim konceptualizacijama obrazovanja koje bi poboljšale školovanje manjinskih migrantskih skupina.

Četvrta cjelina Higher Education odnosi se na iskustva manjina u visokom obrazovanju. Fokus je na metodološkim, teorijskim i praktičnim posljedicama utjecaja kulture, statusa, zajednice, ali i dominantnih diskursa koji se odražavaju na iskustva manjinskih studenata. Uključujući uvodno poglavlje cjelina se sastoji od četiri rada koji naglašavaju svakodnevne izazove u životu i poslu nastavnika koji poučavaju međunarodne studente u Australiji te iskustva afričkih migrantskih studenata i latinoameričkih nedokumentiranih studenata u Sjedinjenim Američkim Državama. Svi radovi naglašavaju potrebu za boljim razumijevanjem navedenih manjinskih skupina, koje bi, prema svim autorima ove cjeline, pridonijelo poboljšanju njihovih obrazovnih postignuća.

Pet radova čini petu cjelinu Religion and Learning koja propituje složenu i osjetljivu povezanost vjerskih manjina i obrazovnih struktura, pri čemu se posebno razmatraju »razvijajući diskurzivni koncepti nacionalne pripadnosti i identiteta u kontekstu u kojem su procesi formiranja i reprodukcije vjerovanja osjetljivi na primjenu državne moći« (str. 4). Autori ovih radova na normativnoj, policy i empirijskoj 
razini većinom obrađuju uobičajene teme vezane uz odnos religije i obrazovanja, pri čemu se škole razmatraju kao lokacije »konflikta između političkih programa integracije i pokušaja manjinskih skupina da očuvaju svoje pravo na samoodređenje i očuvanje svoje kulturne i vjerske različitosti« (str. 522). U radovima se također susreće zajednička tema postkolonijalnog otpora sekularnom obrazovanju, koje se upotrebljava kao sredstvo asimilacije. Posebice na primjeru hindusa ističe se nerazmjer $u$ pogledu upotrebe slobode obrazovnih načela, odnosno smanjenih mogućnosti izražavanja te slobode kod perifernih manjina, koje slabo posjeduju različite oblike moći i društvenoga kapitala, pri čemu se razmatraju struktura i priroda društvenih nejednakosti koje se izravno odražavaju na vjerske manjine.

Nešto veća, zadnja cjelina Community, Work and Learning sadržava devet poglavlja koja, prema uvodnim riječima Georgine Tsolidis, »odlično ilustriraju Bourdieuovu postavku da obrazovatelji trebaju uzeti u obzir moć i njenu nejednaku raspodjelu u društvu « (str. 587, istaknula M. G.), pri čemu se fokus stavlja na kulturne različitosti i složene odnose obrazovanja i moći. U radovima se analiziraju usvojeni obrazovni procesi koji se općenito ne tiču samo razreda i školske okoline već i cijele zajednice i obiteljskog okruženja, i to na primjerima širokog razumijevanja obrazovanja u Brazilu i Dubaiju te na primjeru iskustava manjinskih učenika u Grčkoj, SAD-u, Australiji i na Cipru. Skupno gledano, ova cjelina ocrtava na koji se način učenje odigrava u različitim dinamičnim društvenim odnosima (uključujući i one koji se tiču posla i kulturnih praksi) te kako se transformacija učenja odvija na vrlo širokom spektru aktivnosti, od primjerice onih u okviru svakodnevnih praksi (na primjer ples) do onih ekstremnijih kojih se odnose na kurikulume kreirane tako da prizivaju nacionalni identitet $\mathrm{u}$ konfliktnim situacijama.

U zadnjem poglavlju zbornika urednici iznose zaključna razmatranja, pri čemu naglašavaju važnost istraživanja obrazovanja manjinskih skupina i razumijevanje njihova položaja u obrazovnom sustavu različitih društava.

Općenito, radovi u zborniku detaljno prikazuju obrazovne sustave koji proizvode i održavaju trenutačni nejednaki pristup socijetalnim resursima, pri čemu se migrantske i manjinske skupine depriviraju u razvijanju vlastitih kapaciteta i mogućnosti. Nudi se širok spektar uvida u položaj i mehanizme uključenosti manjina $\mathrm{u}$ obrazovni sustav obrađen kroz različite metodološke pristupe i u različitim društvenim sredinama, uključujući i hrvatsku. Stoga bi ovaj opsežni, raznoliki i detaljni zbornik trebao postati nezaobilazan svakom istraživaču koji se bavi proučavanjem obrazovanja manjinskih skupina, ali i svim akterima uključenima $u$ obrazovni proces, a ponajprije nastavnicima koji sudjeluju u obrazovanju manjinskih i migrantskih skupina.

\section{Margareta Gregurović}

Institut za migracije i narodnosti, Zagreb 